\title{
Aproximações entre percepção de usuários e itens do instrumento para avaliação dos serviços brasileiros em síndrome de imunodeficiência adquirida
}

| ${ }^{1}$ Laura Olinto Dossena, ${ }^{2}$ Rogério Lessa Horta, ${ }^{3}$ Nemora Tregnago Barcellos |

Resumo: $\mathrm{O}$ artigo traz uma avaliação de um serviço especializado em síndrome de imunodeficiência adquirida, no sul do Brasil, relacionando as percepções de usuários com as dimensōes do questionário eletrônico - usado no país para avaliação dos serviços especializados. As perspectivas centrais do estudo são os conceitos de integralidade e humanização da atenção. Foram realizados grupos focais submetidos à análise temática de conteúdos. Os elementos acolhimento e acesso apareceram com destaque entre itens não captados pelo questionário em uso. Tais itens também influenciam o estabelecimento de vínculo, a adesão ao tratamento e a preferência pelo serviço. A pressão de demanda, que interfere negativamente na relação usuário-serviço, também foi captada em detalhes, assim como itens de descontentamento, mesmo predominando uma avaliação positiva do serviço. O preconceito de pessoas vivendo com a síndrome e o que recai sobre elas também se sobressaem, evidenciando a necessidade de organização de práticas em saúde específicas, bem como estudos mais aprofundados sobre o tema. O trabalho mostra a pertinência da inclusão de usuários nas avaliações de serviços de saúde para a qualificação da assistência e ressalta itens que podem ser aproveitados na ampliação e qualificação do instrumento de avaliação dos serviços.

> Palavras-chave: instalações de saúde; recursos humanos; qualificação de assistência; síndrome de imunodeficiência adquirida; grupos focais.

\author{
1 Hospital Sanatório Partenon, \\ Secretaria Estadual de \\ Saúde do Rio Grande do \\ Sul. Porto Alegre-RS, Brasil \\ (lauradossena@gmail.com). \\ 2 Programa de Pós-Graduação \\ em Saúde Coletiva, \\ Universidade do Vale dos \\ Sinos. São Leopoldo-RS, Brasil \\ (rogeriohortamed@gmail.com). \\ ${ }^{3}$ Hospital Sanatório Partenon \\ Secretaria Estadual de Saúde \\ do Rio Grande do Sul. Porto \\ Alegre-RS, Brasil (nemoratb@ \\ gmail.com).
}

Recebido em: 10/10/2015 Aprovado em: 30/12/2016 
No Brasil, desde o primeiro caso de Aids, em 1980, até junho de 2014, foram registrados 757.042 casos da doença. Porto Alegre, cidade sede deste estudo, é a capital com a maior taxa de detecção de Aids registrada em 2013 (BRASIL, 2014). O Departamento DST/Aids e Hepatites Virais, do Ministério da Saúde, estruturou a rede de assistência em serviços de diagnóstico (Centro de Testagem e Aconselhamento - CTA) e tratamento (Serviço de Assistência Especializada SAE) em todos os estados brasileiros. Este campo de atenção à saúde e este conjunto de ações e serviços são alvo de medidas de avaliação, eventual ou rotineiramente.

O principal instrumento de avaliação desta rede é o Qualiaids. Criado no ano 2000 para avaliar a qualidade das dimensões organizacionais e gerenciais da assistência ambulatorial em HIV/Aids, o Qualiaids é um questionário autoaplicável, respondido pelos gerentes e equipes locais dos serviços, composto por 107 questões reunidas em três dimensões: o processo de assistência, o gerenciamento técnico do trabalho e os recursos (BRASIL, 2008; NEMES et al., 2004). Em 2007, o Sistema Qualiaids (Questionário e Guia de Boas Práticas) foi oficialmente implantado pelo Departamento DST/Aids e Hepatites Virais para todos os serviços do país. O Sistema não contempla nenhuma dimensão qualitativa de avaliação.

Avaliação qualitativa pressupõe a apreensão do significado de um fenômeno tal como percebido pelos atores sociais e reconhece a pluridimensionalidade do indivíduo e do processo saúde-doença (BOSI; UCHIMURA, 2006; PINHEIRO; MARTINS, 2009), ancorada na noção ampliada de saúde e na compreensão de saúde como direito de cidadania, com base nas dimensões integralidade, humanização e qualidade (BOSI; UCHIMURA, 2006). Integralidade pode ser definida como um eixo norteador de novas formas de ação e de gestão de cuidados (PINHEIRO; LUZ, 2007), possibilitando novos arranjos sociais e institucionais (PINHEIRO; GUIZARDI, 2005). A humanização da atenção abrange a democratização das relações, com o reconhecimento da alteridade e o diálogo entre os sujeitos no processo terapêutico (BENEVIDES; PASSOS, 2005; DESLANDES, 2005; TEIXEIRA, 2005). A qualidade da atenção tem uma dimensão técnica, de boas práticas e aplicação adequada do que se preconiza para cada condição clínica, mas também tem uma dimensão relacional, totalmente 
dependente dos conceitos de integralidade e humanização da atenção. Nesse sentido, saber o que os usuários de um serviço de saúde para portadores de HIV/ Aids pensam do serviço ao qual estão vinculados e comparar suas percepções e prioridades no exercício avaliativo ao instrumento quantitativo empregado pela rede pública de saúde parece oportuno e desafiador.

Este estudo consistiu na avaliação por um grupo de usuários de um serviço de assistência especializada em HIV/Aids no município de Porto Alegre, RS, seguido do exame das relações possíveis entre as percepções emergentes do grupo e as dimensões do Qualiaids quanto à assistência, à gerência e aos recursos, na perspectiva da integralidade e da humanização.

\section{Método}

Estudo com delineamento qualitativo, exploratório, no qual usuários adultos de um SAE da Secretaria Estadual da Saúde (SES), em Porto Alegre, foram convidados a participar de grupos focais com o propósito de avaliar o serviço e o atendimento que recebiam ali. $\mathrm{O}$ universo empírico da investigação foi selecionado por conveniência. Ao comparecerem para atendimento, as pessoas eram convidadas a participar de um encontro onde se daria oportunidade de avaliarem o serviço e o atendimento que recebiam. Os encontros eram organizados no mesmo dia em que se concentravam as agendas, para facilitar a participação. Quando se chegava a um número mínimo de seis participantes, não havendo outras pessoas em espera por atendimento, os convites cessavam e se desenvolvia o grupo. Novos convites eram feitos em outra data. Foram realizados, ao todo, três grupos, dois com seis participantes e um com sete. Houve, ao todo, 15 recusas, e 19 usuários, ao todo, participaram, sendo 11 homens e oito mulheres, com idades que variaram de 29 a 59 anos. A maioria dos usuários que se recusaram a participar alegaram compromissos profissionais e alguns apenas não se interessaram. Os convites foram suspensos à medida que a realização dos grupos e a análise preliminar evidenciaram saturação e tendência à repetição das informações. Todos os participantes faziam uso de antirretrovirais e a maioria já acessava o serviço há vários anos.

O SAE estudado conta com ambulatório adulto e infantil, hospital-dia, CTA e farmácia onde funciona o Siclom (Sistema de Informação de Controle Logístico de Medicamentos). O ambulatório oferece consultas de infectologia, ginecologia 
e obstetrícia, dermatologia, psiquiatria, psicologia, serviço social, fisioterapia, odontologia, nutrição e enfermagem e nele são desenvolvidas atividades de adesão com grupos de Início de Tratamento e de Manutenção do Tratamento. Sendo referência estadual, esse serviço atende usuários de outros municípios também.

A coleta dos dados foi realizada no período de 11 de março a 6 de maio de 2011. Utilizou-se a técnica de grupo focal, com o objetivo de obter informações, aprofundando a interação entre os participantes, a fim de captar as diferentes visões sobre o tema (VICTORA; KNAUTH; HASSEN, 2000).

Os encontros foram coordenados por duas pesquisadoras, sendo um deles sempre a primeira autora deste artigo, que fazia o papel de moderadora. A segunda pesquisadora tinha o papel de observadora, para anotar os acontecimentos de maior interesse e auxiliar na observação da comunicação não verbal. Os participantes eram acolhidos em sala reservada no próprio serviço, habitualmente usada para atividades de grupo, climatizada, com cadeiras dispostas em círculo. Os encontros não sofreram qualquer tipo de interrupção.

Os participantes não examinaram o Qualiaids nem sua estrutura foi apresentada nos encontros. A moderadora iniciava a atividade agradecendo a disponibilidade dos participantes e falando sobre a importância de se saber o que os usuários pensam do serviço ao qual estão vinculados, pedindo que falassem livremente sobre como se sentem quando estão no serviço, que dificuldades e facilidades encontram, que qualidades percebem e que críticas teriam a fazer. No momento que a coordenação percebeu que o grupo se investiu do propósito de falar sobre o serviço, indicou as questôes centrais do estudo, uma de cada vez e, se possível, aproveitando emergentes grupais relacionados à questão: Como é o atendimento no serviço? O que os deixa satisfeitos? O que os deixa insatisfeitos? Não necessariamente a questão foi proposta na forma de pergunta, mas frequentemente apenas estimulando que o grupo explorasse o tema que já havia surgido. A moderadora buscou estimulá-los a falar sobre diferentes etapas ou atividades inerentes ao atendimento no serviço, caso não emergissem livremente, como: o acolhimento e o acesso ao serviço; os horários, as rotinas e os prazos de agendamento de consultas; o atendimento, as orientações e aconselhamentos, as atividades de adesão e a comunicação serviço-usuáriocomunidade; a infraestrutura básica, os medicamentos, exames, atendimentos complementares (referências) e a atualização dos profissionais. A moderadora 
não corrigiu nem julgou, mas zelou para que o grupo se mantivesse no tema, propondo questões complementares ou recolocando as questões sempre que havia dispersão ou esfriamento da discussão no grupo. Também zelou para que ninguém do grupo assumisse o papel de censura às ideias dos demais, ligando este cuidado à preocupação de conhecer o material emergente da discussão em seu conjunto, sem necessidade do grupo chegar a um veredicto. Não foram feitas sínteses intermediárias. Não houve conflitos ou constrangimentos entre os participantes. Ao final de cada grupo foi oferecido um lanche aos participantes.

Cada encontro foi gravado e transcrito para análise dos emergentes grupais, que foram reunidos nos eixos temáticos (BARDIN, 2010), com categorias definidas previamente (as mesmas das dimensões do Qualiaids): na dimensão assistência: Orientação e Aconselhamento, Acolhimento, Organização e rotina geral da assistência de enfermagem, Organização e rotinas da assistência de outros profissionais, Organização e rotinas da assistência médica, Organização geral do trabalho, Atividades específicas de adesão ao tratamento; na dimensão gerência: Registros, avaliação, monitoramento e planejamento, Atualização dos profissionais, Coordenação do trabalho, Comunicação e interação ServiçoUsuários-Comunidade, na dimensão recursos: Acesso, Infraestrutura básica, Recursos humanos, Medicamentos, exames e referências; e também em categorias nativas que surgiram ao longo da análise, não contempladas no questionário eletrônico nem estabelecidas previamente, como construto teórico do projeto - preconceito (na dimensão assistência) e Gestor/Setor Saúde (na dimensão gerência).

O projeto foi aprovado pelo Comitê de Ética em Pesquisa da Escola de Saúde Pública da SES/RS, sob o no 583/10. Todos os sujeitos que concordaram em participar do estudo assinaram o Termo de Consentimento Livre e Esclarecido.

$\mathrm{Na}$ apresentação dos dados nas tabelas que acompanham os resultados, os seguintes critérios foram utilizados:

a) a expressão IDEM na coluna de registros dos usuários indica que o emergente grupal confirma o que é avaliado no item correspondente no Qualiaids, sem qualquer contribuição adicional;

b) a expressão $T A M B E M$, seguida de uma informação, traduz a sugestão que os autores fazem de ampliação da avaliação naquele item, tendo por base manifestações dos usuários resumidas na informação que completa a frase; 
c) a indicação NATO CONSTA, quando aparece na coluna do Qualiaids, revela emergentes grupais que não estão no instrumento e que os autores sugerem sejam considerados para ampliação do mesmo;

d) a informação NÃO SE MANIFESTARAM indica itens do Qualiaids não abordados pelos usuários.

Os resultados foram agrupados nos três eixos temáticos, correspondentes a cada uma das grandes dimensões do Qualiaids, relacionando as questôes propostas no instrumento com os emergentes grupais (quadros 1, 2 e 3).

\section{Resultados}

As manifestações dos usuários são resumidas nos quadros 1, 2 e 3, em paralelo aos itens que constituem o instrumento do Qualiaids, de acordo com os critérios definidos na metodologia.

\section{Dimensão Assistência}

O quadro 1 apresenta os aspectos destacados nos grupos focais e os itens propostos para avaliação da assistência no Qualiaids. Serão priorizados aqui os itens que emergiram dos grupos focais e não constam do Qualiaids. Destaca-se, assim, a categoria Preconceito, que emergiu de reflexões e queixas formuladas com exemplos oriundos de diferentes ambientes. Em suas inserções profissionais, as justificativas repetidas de ausência, decorrentes de o atendimento só ser oferecido em dias e horários úteis, que coincidem com suas atividades profissionais, terminam por determinar algum grau de exposição. A sequência de atestados de comparecimento aos serviços especializados em HIV/Aids acaba por identificálos e é comum perceberem reações desagradáveis em seus ambientes de trabalho. Além de precisarem faltar para vir às consultas, por vezes frequentes, os atestados terminam comprometendo o sigilo sobre sua doença, já que o serviço éidentificado. Percebem o preconceito entre si também, ou por sentirem necessidade de manter a doença em sigilo, ou quando evitam falar, entre eles, na sala de espera, de sua condição de soropositivos. Sugeriram que se promovessem atividades de sala de espera e apontaram a necessidade de se pensar estratégias no serviço para lidar com o mesmo. O serviço não oferecer horários alternativos, não propor reflexões sobre o tema e a percepção deles de que alguns funcionários são preconceituosos, 
foram indicados como participação do serviço no agravamento daquilo que indicaram enfrentar como preconceito. $\mathrm{O}$ preconceito de alguns funcionários foi referido através das percepçōes de descortesias, frieza e distanciamento em algumas situações de atendimento, ou ainda à evitação direta de contato físico ou interlocução mais demorada com os pacientes. Alguns também disseram que preferem ser atendidos rapidamente para não serem vistos frequentando um serviço de HIV/Aids, o que nem sempre se viabiliza. Outros referiram ter optado por um serviço fora de sua cidade de origem para não serem reconhecidos lá.

Os usuários enfatizaram também a importância de os serviços proporem reuniões ou outros estímulos que enfrentem o preconceito em relação à vida com HIV/Aids. Eles não esperam que não ocorra preconceito, mas que isso seja enfrentado no cotidiano dos serviços. Este último item não foi relacionado no Quadro 1 em Preconceito, mas como parte da Organização Geral do Trabalho. Ainda como item desta categoria que não consta do Qualiaids, foi indicada a necessidade de se buscar saber se eles, usuários, estão achando o serviço bom e se percebem que o atendimento vai melhorando ou se houve piora.

Grupo 3: [...] então, vê esse trabalho que a gente tá fazendo aqui de reunir, poderia ser numa sala que tivesse uma sala adequada de repente até com as pessoa, até passar essas informações, ou seja, olha a gente tá mudando nosso sistema, a gente tá tentando fazer uma melhoria, talvez até buscar opiniōes dos pacientes porque somos nós que vamos usar essa melhoria e pra ver, decidir junto, quem sabe o que melhor fazer pra ser melhor atendido.

Os participantes referiram ainda que facilitaria seu retorno e se evitaria perda de contato com o serviço, se fossem procurados sempre que faltam. Isso foi anotado no Quadro 1 como concordância com o item de convocação dos faltosos, mas eles informaram que, ao esquecerem uma consulta ou se ficam impossibilitados de comparecer, por questôes profissionais ou de outra ordem, sentem-se constrangidos e, algumas vezes, tentam contato para novo agendamento, mas encontram várias dificuldades, como telefone sempre ocupado, indisponibilidade de agenda ou do atendente para fazer o agendamento, limitação de horário do serviço, além do preconceito que eventualmente se reapresenta em intervenções pejorativas por precisarem do serviço e não terem aproveitado agendamento feito. Disso, emergiram queixas sobre a marcação de consultas ou atendimentos, tanto em retornos, como no acolhimento, itens que também não constam do instrumento em uso. 

do SAE-Porto Alegre e os itens da Dimensão Assistência do Qualiaids, 2011

\begin{tabular}{|c|c|c|}
\hline Itens & Qualiaids* & Usuários \\
\hline $\begin{array}{l}\text { Orientação e } \\
\text { Aconselhamento }\end{array}$ & $\begin{array}{l}\text { - Aconselhamento pré e pós-teste (se } \\
\text { faz; por quem; individual ou grupo) } \\
\text { - Atividades em sala de espera (se } \\
\text { tem, como) } \\
\text { - Direitos reprodutivos (condutas dos } \\
\text { profissionais) } \\
\text { - Orientação sobre o uso de ARV } \\
\text { (grupos de adesão e/ou consultas, } \\
\text { quem faz) }\end{array}$ & $\begin{array}{l}\text { - TAMBÉM se aconselhamento } \\
\text { adequado e suficiente } \\
\text { - IDEM } \\
\text { - NÃO SE MANIFESTARAM } \\
\text { - TAMBÉM se orientações adequadas } \\
\text { e suficientes }\end{array}$ \\
\hline Acolhimento & $\begin{array}{l}\text { - } 1^{\circ} \text { atendimento: prontidão e } \\
\text { resolutividade (atendido no dia ou } \\
\text { agendado, ou orientado retorno; } \\
\text { qual profissional; atividades; se } \\
\text { encaminhado a outro serviço e como; } \\
\text { se agenda consulta de retorno e prazo) } \\
\text { - NÃO CONSTA } \\
\text { - Não consta } \\
\text { - Não consta }\end{array}$ & $\begin{array}{l}\text { TAMBÉM se o atendimento é } \\
\text { humanizado em todos os momentos, } \\
\text { não só no primeiro atendimento e se } \\
\text { melhorou ou piorou } \\
\text { - Se o ambiente é bom e sua } \\
\text { qualidade está sendo preservada } \\
\text { - Considerar a marcação de consulta } \\
\text { de rotina na avaliação do acolhimento } \\
\text { - Se a integração entre funcionários } \\
\text { melhora o acolhimento }\end{array}$ \\
\hline $\begin{array}{l}\text { Assistência de } \\
\text { enfermagem }\end{array}$ & $\begin{array}{l}\text { - Atendimentos de enfermagem } \\
\text { (pré-consulta de rotina e pós- } \\
\text { consulta, finalidade; atividades do } \\
\text { auxiliar/técnico) } \\
\text { - Atividades e rotina do enfermeiro } \\
\text { (atividades; consulta individual) }\end{array}$ & $\begin{array}{l}\text { - TAMBÉM a qualidade do } \\
\text { atendimento } \\
\text { - TAMBÉM a qualidade do } \\
\text { atendimento }\end{array}$ \\
\hline $\begin{array}{l}\text { Assistência } \\
\text { de outros } \\
\text { profissionais }\end{array}$ & $\begin{array}{l}\text { - Atendimento odontológico: acesso } \\
\text { e organização } \\
\text { - Atendimento do psicólogo, do } \\
\text { assistente social, do farmacêutico } \\
\text { (atividades e atribuições) }\end{array}$ & $\begin{array}{l}\text { - TAMBÉM a qualidade do } \\
\text { atendimento } \\
\text { - TAMBÉM a qualidade do } \\
\text { atendimento }\end{array}$ \\
\hline
\end{tabular}




\begin{tabular}{|c|c|c|}
\hline Itens & Qualiaids* & Usuários \\
\hline $\begin{array}{l}\text { Assistência } \\
\text { médica }\end{array}$ & $\begin{array}{l}\text { - Tempo das consultas médicas ( } \mathrm{n}^{\circ} \text { de } \\
\text { consultas/4 h; casos novos/médico e } \\
\text { duração consulta inicial e de retorno) } \\
\text { - Vínculo (rotina do agendamento } \\
\text { das consultas de retorno) } \\
\text { - Trabalho dos médicos infectologistas } \\
\text { e clínicos (condutas na consulta) } \\
\text { - Trabalho do médico ginecologista } \\
\text { (acesso às consultas) } \\
\text { - Intervalo entre consultas médicas } \\
\text { - Atendimento médico para não } \\
\text { agendados (condutas, demandas, } \\
\text { atividades) }\end{array}$ & $\begin{array}{l}\text { - IDEM } \\
\text { - IDEM } \\
\text { - TAMBÉM a qualidade do } \\
\text { atendimento } \\
\text { - NĀO SE MANIFESTARAM } \\
\text { - TAMBÉM se melhorou ou piorou } \\
\text { - NÃO SE MANIFESTARAM }\end{array}$ \\
\hline $\begin{array}{l}\text { Organização } \\
\text { geral do } \\
\text { trabalho }\end{array}$ & $\begin{array}{l}\text { - NÃO CONSTA } \\
\text { - Convocação de faltosos (se há, } \\
\text { conduta) } \\
\text { - Fluxo de encaminhamento entre } \\
\text { profissionais } \\
\text { - Padronização de condutas (se } \\
\text { existem protocolos, onde e como } \\
\text { foram elaborados) } \\
\text { - NÃO CONSTA } \\
\text { - NÃO CONSTA }\end{array}$ & $\begin{array}{l}\text { - Considerar se há organização } \\
\text { de reuniões para falarem de seus } \\
\text { problemas } \\
\text { - IDEM } \\
\text { - NÃO SE MANIFESTARAM } \\
\text { - TAMBÉM se há organização } \\
\text { no funcionamento cotidiano e a } \\
\text { existência de alinhamento entre os } \\
\text { setores do serviço } \\
\text { - Considerar a forma de marcação de } \\
\text { consulta médica } \\
\text { - Se o serviço é bom, melhorou ou } \\
\text { piorou }\end{array}$ \\
\hline $\begin{array}{l}\text { Atividades } \\
\text { de adesão ao } \\
\text { tratamento }\end{array}$ & $\begin{array}{l}\text { - Adesão: rotinas e orientações } \\
\text { para o uso de ARV (uso correto/ } \\
\text { dificuldades no uso) } \\
\text { - Medicação fora de rotina (acesso, } \\
\text { orientaçôes) }\end{array}$ & $\begin{array}{l}\text { - TAMBÉM se adequada e suficiente } \\
\text { - IDEM }\end{array}$ \\
\hline Preconceito & $\begin{array}{l}\text { - NÃO CONSTA } \\
\text { - NÃO CONSTA }\end{array}$ & $\begin{array}{l}\text { - Considerar se existem atividades } \\
\text { sobre o tema preconceito para } \\
\text { pacientes e funcionários } \\
\text { - Os atendimentos implicam } \\
\text { exposição no ambiente de trabalho }\end{array}$ \\
\hline
\end{tabular}

* Entre parênteses, o conteúdo das perguntas do questionário. 
A atitude acolhedora, de escuta e atendimento dos profissionais ante as necessidades de saúde dos usuários é percebida no serviço estudado, conforme relatado pelos participantes. O ambiente foi considerado bom e, em geral, relataram se sentir bem quando circulam por ele. Não há no Qualiaids um item que contemple esta informação, que foi incluída como parte da categoria Acolhimento, no Quadro 1. Alguns pacientes chegaram a dizer que se sentem em casa, quando se referiam à satisfação com o atendimento e com as consultas prestadas, e muitos já estão em acompanhamento há anos. Isso não impediu que alguns aspectos a ser melhorados fossem apontados.

Algumas falas nos grupos traduzem a percepção de características do processo de trabalho condizentes com princípios da humanização nos atendimentos oferecidos no serviço, excetuando-se algumas situações pontuais, em relação às quais foi sugerido que houvesse uma maior integração entre os diversos setores que compõem o serviço. Em suas falas, isso os levaria a se sentirem mais bem acolhidos. Entendido este ponto como um item de avaliação, que não encontrou correspondente no Qualiaids, ele foi também inserido na categoria Acolhimento.

Outro registro que merece destaque é a ideia de que a qualidade dos atendimentos de todos os profissionais fosse considerada, não apenas a oferta ou não do serviço, como consta do Qualiaids. Os participantes foram incisivos ao fazerem reflexōes envolvendo a qualidade dos atendimentos. De um modo geral, foi referida satisfação. Alguns participantes disseram que as orientaçôes sobre alimentação e cuidados foram poucas, os demais referiram que foram bem orientados.

Chamaram atenção, também, para a necessidade de se avaliar se a marcação de consultas tem caráter acolhedor e facilitador do agendamento.

\section{Dimensão Gerência}

$\mathrm{Na}$ dimensão Gerência (quadro 2), poucos itens foram coincidentes entre os emergentes grupais e os itens do instrumento. A maioria dos itens do instrumento não apareceu na fala dos usuários. Percebe-se que eles discutem temas relacionados ao gerenciamento em itens que são, na verdade, desdobramentos dos procedimentos gerenciais, que eventualmente entendem até como desrespeito pelas dificuldades encontradas pelos usuários no acesso às informações e aos processos de agendamento e atendimento. Como emergentes grupais que 
não correspondem a variáveis do Qualiaids, nesta dimensão, apareceram as seguintes indicações: considerar se há investimento no paciente desde o início, como dado no item avaliação e monitoramento; incluir capacitação dos funcionários (equipes de apoio e serviços meio) e considerar se há substituição dos profissionais durante capacitações, como dados no item atualização; avaliar se há disponibilização de informaçôes sobre matérias veiculadas pela mídia, no item interação serviço-usuário-comunidade; considerar adequação do serviço às necessidades de saúde, quanto a recursos do sistema, responsabilidade e investimentos da gestão (quadro 2).

Além disso, os grupos indicaram a necessidade de ampliação do escopo em dois itens: quanto à capacitação e experiência dos profissionais, verificar, de alguma forma, se estão atualizados, não sendo suficiente que tenham titulação ou experiências acumuladas; quanto à comunicação com usuários e comunidades, considerar se há espaços de reunião entre profissionais e pacientes para informar mudanças nas rotinas do serviço e levantar a opinião dos usuários (quadro 2).

Quadro 2. Comparação entre aspectos emergentes dos grupos focais com usuários do SAE-Porto Alegre e os itens da Dimensão Gerência do Qualiaids, 2011

\begin{tabular}{|c|c|c|}
\hline Itens & Qualiaids* & Usuários \\
\hline $\begin{array}{l}\text { Registros, } \\
\text { Avaliação, } \\
\text { Monitoramento } \\
\text { e Planejamento }\end{array}$ & $\begin{array}{l}\text { - Controle de faltosos (quantos > } 13 \\
\text { anos faltaram no último mês) } \\
\text { - Prontuários: arquivo e registros de } \\
\text { atendimentos } \\
\text { - Registro rotineiro de dados e } \\
\text { avaliaçōes } \\
\text { - Prontuários padronizados } \\
\text { - Vigilância epidemiológica: } \\
\text { notificação compulsória (quem faz) } \\
\text { - Critério de abandono (se há, quais) } \\
\text { - Registro e controle de óbitos (se } \\
\text { há, modo) } \\
\text { - Controle e distribuição dos ARV } \\
\text { - Planejamento de atividades (se há, } \\
\text { como) } \\
\text { - NÃO CONSTA }\end{array}$ & $\begin{array}{l}\text { - NÃO SE MANIFESTARAM } \\
\text { - NĀO SE MANIFESTARAM } \\
\text { - IDEM } \\
\text { - NÃO SE MANIFESTARAM } \\
\text { - NÃO SE MANIFESTARAM } \\
\text { - NÃO SE MANIFESTARAM } \\
\text { - NÃO SE MANIFESTARAM } \\
\text { - Não se manifestaram } \\
\text { - Não se manifestaram } \\
\text { - Considerar se há investimento no } \\
\text { paciente desde o início do tratamento }\end{array}$ \\
\hline
\end{tabular}

continua... 


\begin{tabular}{|c|c|c|}
\hline Itens & Qualiaids* & Usuários \\
\hline $\begin{array}{l}\text { Atualização dos } \\
\text { profissionais }\end{array}$ & $\begin{array}{l}\text { - Capacitação e experiência dos } \\
\text { profissionais (se há incentivo do } \\
\text { serviço) } \\
\text { - Acesso a textos e materiais de } \\
\text { consulta (no serviço) } \\
\text { - NÃO CONSTA } \\
\text { - NÃO consta }\end{array}$ & $\begin{array}{l}\text {-TAMBÉM se os profissionais estão } \\
\text { atualizados } \\
\text { - NÃO SE MANIFESTARAM } \\
\text { - Considerar se há substitutos quando } \\
\text { profissionais saem para capacitações } \\
\text { - Incluir a capacitação dos } \\
\text { funcionários }\end{array}$ \\
\hline $\begin{array}{l}\text { Coordenação do } \\
\text { trabalho }\end{array}$ & $\begin{array}{l}\text { - Reuniōes de equipe (se há, frequência) } \\
\text { - Coordenação técnica e } \\
\text { administrativa (quem faz) } \\
\text { - Suporte e supervisão aos } \\
\text { profissionais (se há, quais) } \\
\text { - Resolução de problemas e } \\
\text { dificuldades (medidas tomadas) }\end{array}$ & $\begin{array}{l}\text { - Não se manifestaram } \\
\text { - IDEM } \\
\text { - NÃO SE MANIFESTARAM } \\
\text { - IDEM }\end{array}$ \\
\hline $\begin{array}{l}\text { Comunicação } \\
\text { e interação } \\
\text { Serviço- } \\
\text { Usuários- } \\
\text { Comunidade }\end{array}$ & $\begin{array}{l}\text { - Participação institucional dos } \\
\text { usuários e interação serviço- } \\
\text { comunidade (forma organizada } \\
\text { para encaminhar reclamações; } \\
\text { participação organizada dos pacientes } \\
\text { no encaminhamento de soluções; } \\
\text { integração rotineira intersetorial) } \\
\text { - NÃO consta }\end{array}$ & $\begin{array}{l}\text { - TAMBÉM se há espaços de reunião } \\
\text { entre profissionais e pacientes para } \\
\text { informar mudanças e buscar opinião } \\
\text { dos usuários; se comunicação } \\
\text { adequada e suficiente } \\
\text { - Considerar a disponibilização de } \\
\text { informações sobre novidades da } \\
\text { mídia }\end{array}$ \\
\hline $\begin{array}{l}\text { Gestor/Setor } \\
\text { Saúde }\end{array}$ & - NÃO CONSTA & $\begin{array}{l}\text { - Considerar os recursos do sistema, } \\
\text { a responsabilidade e o investimento } \\
\text { do gestor na adequação do serviço às } \\
\text { necessidades de saúde }\end{array}$ \\
\hline
\end{tabular}

*Entre parênteses, o conteúdo das perguntas do questionário.

A crítica mais referida, que tem a ver com recursos do sistema, responsabilidade e investimentos da gestão, anotada como item de avaliação do Gestor, que não consta no Qualiaids, indica que a maioria das consultas é marcada para o mesmo horário em cada turno e o atendimento se dá por ordem de chegada, além de o agendamento ser feito sempre e apenas no dia 25 de cada mês.

Grupo 2: [...] essas marcação de consulta, dia 25... tá judiando. [...] agora, eles têm três ou quatro telefone ali ó. Pode ligar agora do teu aí pra ver se alguém atende. [...] Sei que dia vinte e cinco ... dia 25 é cruel. 
Grupo 3: [...] Eles não explicaram. É só agora vem marcar consulta: Ah, é só por telefone, dia 25 ainda. Porque dia 25? Isso no caso tu vai precisar morrer tu tem que ser depois do dia 25? Vai morrer é depois do dia 25? Ou se pega uma doença tem que ser só depois do dia 25?

Antigamente, os usuários já saíam da consulta médica com os exames e a próxima consulta agendados. $\mathrm{O}$ intervalo entre elas era de três a quatro meses. Agora é de seis meses, às vezes ficando oito meses sem consultar por dificuldade em conseguir agendamento. Constataram que o serviço está perdendo a qualidade. $\mathrm{O}$ atendimento é humanizado, mas já foi melhor. Disseram que os profissionais são empenhados em atender bem, mas percebem que algumas dificuldades presentes escapam ao contexto do serviço, são de responsabilidade do gestor.

Grupo 1: [...] não, é que falta condição de investimento de verba do governo. Tá faltando $[\ldots]$.

Foi referido que os responsáveis pelos serviços deveriam aumentar o número de profissionais, tanto médicos, enfermeiros, como da área administrativa, para dar conta da crescente demanda de atendimentos. Sentem-se desrespeitados. Falaram que é direito do usuário ter o médico para atendê-lo e é responsabilidade do setor da saúde. Responsabilizam os gestores pela falta de investimento.

$\mathrm{Na}$ época da coleta de dados, o serviço passava por uma série de adequações, o que implicava a troca de um número significativo de funcionários na área administrativa. Isso possivelmente está vinculado à identificação da necessidade de buscar estratégias para melhorar a comunicação entre todos, incluindo-se aí a falta de informação sobre as mudanças que vinham ocorrendo no serviço. Os participantes comentaram que, mesmo assim, ainda é um serviço "maravilhoso", mas se mostraram atentos e sensíveis às transiçōes vividas.

\section{Dimensão Recursos}

$\mathrm{Na}$ análise dos emergentes grupais identificados com o tema dos Recursos, na estrutura do Qualiaids (quadro 3), percebeu-se que os usuários tenderam a acompanhar as questôes que já compõem o instrumento, mas dois itens mereceram o registro como não constando do instrumento: a necessidade de se verificar se as equipes administrativas são suficientes e adequadas, em Recursos Humanos, e, em Medicamentos, Exames e Referências, a possibilidade de verificar se os serviços têm o cuidado de oferecer sacolas na entrega dos medicamentos, evitando a exposição pública dos medicamentos em uso. 

do SAE-Porto Alegre e os itens da Dimensão Recursos do Qualiaids, 2011

\begin{tabular}{|c|c|c|}
\hline Itens & Qualiaids* & Usuários \\
\hline Acesso & $\begin{array}{l}\text { - Horário de funcionamento do serviço } \\
\text { (dias/semana, horas/dia) } \\
\text { - Horários de agendamento (modo de } \\
\text { agendamento) } \\
\text { - Local de dispensação dos ARV (se } \\
\text { serviço dispensa ou a relação com serviço } \\
\text { de referência) } \\
\text { - Coleta de exames (se coleta ou } \\
\text { encaminha) }\end{array}$ & $\begin{array}{l}\text { - TAMBÉM se adequado e } \\
\text { suficiente } \\
\text { - TAMBÉM se adequados, } \\
\text { suficientes e acesso às consultas } \\
\text { - IDEM } \\
\text { - IDEM }\end{array}$ \\
\hline $\begin{array}{l}\text { Infraestrutura } \\
\text { básica }\end{array}$ & $\begin{array}{l}\text { - Estrutura física e biossegurança ( }{ }^{\circ} \\
\text { de consultórios/salas para atendimento; } \\
\text { acesso a transporte; planta física versus } \\
\text { circulação; conduta no acidente com } \\
\text { material biológico; treinamento para } \\
\text { casos de exposição ocupacional; quem } \\
\text { faz o acondicionamento dos resíduos/ } \\
\text { lixo contaminados) }\end{array}$ & $\begin{array}{l}\text { - TAMBÉM se dimensão } \\
\text { do espaço físico e ventilação } \\
\text { adequados }\end{array}$ \\
\hline $\begin{array}{l}\text { Recursos } \\
\text { humanos }\end{array}$ & $\begin{array}{l}\text { - Capacitação e experiência dos } \\
\text { infectologistas e clínicos (tempo médio } \\
\text { de experiência em HIV/Aids se > ou < } \\
5 \text { anos) } \\
\text { - No de médicos (carga horária total/ } \\
\text { semana dos infectologistas/clínicos) } \\
\text { - No de profissionais não médicos } \\
\text { (disponibilidade, quais, quantos, se } \\
\text { exclusivos do serviço) } \\
\text { - Perfil e formação do gerente (formação } \\
\text { do gerente administrativo; experiência } \\
\text { do coordenador técnico em serviços de } \\
\text { HIV/Aids) } \\
\text { - NÃO CONSTA }\end{array}$ & $\begin{array}{l}\text { - Não se manifestaram } \\
\text { - TAMBÉM considerar outras } \\
\text { especialidades } \\
\text { - IDEM } \\
\text { - Não se manifestaram } \\
\text { - Se equipe administrativa } \\
\text { suficiente e adequada }\end{array}$ \\
\hline
\end{tabular}

continua... 


\begin{tabular}{|c|c|c|}
\hline Itens & Qualiaids* & Usuários \\
\hline $\begin{array}{l}\text { Medicamentos, } \\
\text { exames e } \\
\text { referências }\end{array}$ & $\begin{array}{l}\text { - Medicamentos específicos: ARV e } \\
\text { doenças oportunistas (disponibilidade/ } \\
\text { semestre; tempo de dispensação/1ª } \\
\text { prescrição) } \\
\text { - Modalidades assistenciais e } \\
\text { especialistas (se disponível no/fora do } \\
\text { serviço ou indisponível, quais) } \\
\text { - Exames laboratoriais e de Imagem } \\
\text { (disponibilidade e tempo até resultado; } \\
\text { cota disponível de CD4 e carga viral/ } \\
\text { paciente/ano) } \\
\text { - NÃO CONSTA }\end{array}$ & $\begin{array}{l}\text { - IDEM } \\
\text { - TAMBÉM se são difíceis e } \\
\text { demoradas } \\
\text { - IDEM } \\
\text { - Considerar o fornecimento de } \\
\text { sacolas para medicação (evitando } \\
\text { expor medicação utilizada) }\end{array}$ \\
\hline
\end{tabular}

*Entre parênteses, o conteúdo das perguntas do questionário.

Já entre os itens atualmente contemplados no Qualiaids, os usuários solicitaram o aumento do número de médicos, inclusive indicando como critério de avaliação a oferta de diferentes especialidades no serviço. Gostariam de resolver seus problemas de saúde em um mesmo lugar, mesmo porque os encaminhamentos para outros serviços são muito demorados. Alguns estavam esperando agendamento havia mais de um ano, e outros informaram pagar serviços privados. Entendem que seria mais resolutivo se fosse ampliada a oferta de especialidades no serviço, além de evitar a exposição de sua condição de soropositivos ou doentes de Aids em outros serviços.

Muitos itens coincidiram com o Qualiaids e foram mencionados como adequados no serviço. Manifestaram, por exemplo, percepção de melhora no agendamento dos exames de carga viral e CD4, que agora são feitos no próprio local. Saem da consulta médica e já marcam o dia para coleta dos exames, que, depois de prontos, são colocados diretamente nos prontuários. Todos também disseram que é fácil conseguir os medicamentos e que nunca interromperam a medicação por falta de fornecimento da farmácia. Pontuaram o excelente atendimento dos funcionários. No que diz respeito ao espaço físico do serviço, todos os participantes do estudo reclamaram que é muito pequeno, principalmente a sala de espera, fazendo com que algumas pessoas fiquem no pátio aguardando sua chamada para a consulta. Também referiram a pouca ventilação nesse local. 
A sala de espera é um espaço dinâmico, por onde diversas pessoas circulam e aguardam um atendimento de saúde. Em geral, permanecem algumas horas nesse ambiente e manifestaram interesse em aproveitar melhor esse tempo participando de atividades com informações sobre sua doença, trocando experiências, sendo estimulada a prevenção e a adesão. Estes últimos registros sugerem a indicação de critérios de avaliação da qualidade, como conforto e aproveitamento do espaço físico, na avaliação da infraestrutura.

\section{Discussão e conclusões}

A avaliação de serviços de saúde, em especial, aqueles que atendem pessoas vivendo com Aids, tem merecido um debate bastante qualificado (NEMES et al., 2013). Algumas limitações já têm sido apontadas ao Qualiaids e a expectativa de que novas contribuições proponham abordagens diferenciadas e mais qualificadas no processo de avaliação também é mencionada (MELCHIOR et al., 2006).

Preconceito e estigmatização são temas recorrentes em diferentes áreas da atenção em saúde. Garrido et al. (2007) indicam intervenções nos serviços de saúde, como o estímulo à participação em grupos de apoio e compartilhamento, com potencial para minorar o efeito do estigma e da discriminação. Nesse sentido, pensar a avaliação dos serviços especializados em HIV/Aids com a participação dos usuários pode ser um diferencial importante e que se apoia nas evidências deste estudo. A aproximação que se fez aqui da percepção de grupos de usuários sobre o serviço mostra que há itens não contemplados no instrumento hoje empregado e que a qualidade da assistência prestada nos serviços de saúde é uma das principais estratégias para a redução da mortalidade e morbidade relacionadas à Aids, sendo essencial atentar para a diversidade de fatores que a determina. A reorganização do agendamento das consultas e exames de forma que não prejudique os trabalhadores, por exemplo, já foi sugerida por Garrido et al. (2007) para diminuir o efeito do estigma.

Usuários, profissionais de saúde e gestores têm diferentes interesses e perspectivas quanto aos serviços de saúde, priorizando aspectos variados quando avaliam a qualidade das ações de saúde. Isto fica ratificado neste estudo ao relacionar as percepções dos usuários com o Qualiaids, instrumento que é respondido pelos gerentes e equipes locais dos serviços. A avaliação dos processos envolvidos no acolhimento, por exemplo, ganha destaque na primeira dimensão, 
em consonância com a posição de Hennington (2005), que diz que o acolhimento desponta como estratégia essencial das propostas de reorganização da assistência nos distintos serviços de saúde no país, modificando o modelo de atenção tecnoassistencial para o modelo centrado no usuário, desde a sua entrada no sistema de saúde. Teixeira (2007) ressalta a importância do acolhimento-diálogo, fazendo referência à postura que os profissionais e funcionários devem adotar em todos os espaços do serviço por onde circulam os usuários, e a necessidade do funcionamento em rede dentro de um serviço de saúde.

Nesse sentido, Esher e colaboradores (2011, 2012), ao apresentar três modelos lógicos para a avaliação de serviços na assistência farmacêutica, incluem aspectos diversos como estrutura, ambiente de privacidade, limpeza e higiene, além de respeito, empatia e atitude de não julgamento, como indicadores das dimensões de ambiência e de relações interpessoais, muitos deles coincidentes com a concepção de acolhimento que emergiu no nosso estudo.

Fica evidente a pertinência de ouvir os usuários para saber o que pensam e como se sentem no serviço, pois são eles que fazem uso do serviço e devem também decidir sobre as mudanças que ocorrem. Assim se qualifica a assistência prestada, tanto na forma de organização do serviço, quanto nas práticas profissionais, incluindo os usuários como protagonistas nesse processo, respeitando seus direitos de cidadania (RAMOS; LIMA, 2003; SOUZA et al., 2008). O artigo de Nemes et al. (2013), por exemplo, mostrou que as soluções encontradas para viabilizar o acesso a atendimentos especializados e para compatibilizar a demanda por consultas e a quantidade de profissionais disponíveis não têm sido suficientemente resolutivas, assim como informaram os usuários, através de emergentes grupais neste estudo, ao enfatizarem que os atendimentos precisam ser aferidos também em sua qualidade e a gestão, na sua capacidade de substituir os profissionais e tornar os atendimentos disponíveis. Os usuários vão além dos limites estabelecidos pelos itens objetivos do Qualiaids e, aqui, classificaram positivamente o serviço, mesmo pontuando algumas situações de descontentamento, como em relação às medidas adotadas diante da crescente procura por atendimentos no local. A necessidade de flexibilização dos horários está presente e reflete uma organização de serviços que se contrapõe a um regime trabalhista que valoriza a assiduidade e exclui o doente do mundo do trabalho. Esses aspectos demonstram a importância de se considerar as dimensões subjetivas na avaliação da qualidade, mesmo quando se avaliam os recursos, confirmando o que preconizam Bosi e Uchimura (2003). 
Outra questão destacada diz respeito ao reconhecimento do impacto causado pelo preconceito no cotidiano das pessoas vivendo com HIV/Aids e implica a organização de práticas em saúde voltadas para atenuá-lo. No serviço investigado, o acesso às consultas médicas está muito difícil, sendo unânime a insatisfação manifestada pelos entrevistados, inclusive comprometendo o acolhimento e a adesão ao tratamento. Estudos sobre o acesso vêm ressaltando sua importância como um dos fatores que favorecem o vínculo com os usuários, principalmente o referente à oferta de serviços apropriados às suas necessidades de saúde (RAMOS; LIMA, 2003; SOUZA et al., 2008). O acesso que diz respeito à organização e planejamento das práticas em saúde é denominado de acesso funcional. Esse foi um ponto capital de insatisfação de todos os participantes.

Mais importante que a aferição do serviço local foi constatar que a escuta qualificada de grupos de usuários aponta aspectos relevantes que podem ser aproveitados na qualificação do instrumento de avaliação dos serviços neste campo. Sobre este tema, Mishima (2003) e Peduzzi (2011) destacam a importância de se promoverem mudanças, possibilitando o atendimento das necessidades de saúde da população. Salientam que a prática gerencial deve utilizar tecnologias relacionais, estabelecendo relações mais acolhedoras com os usuários, buscando formas de participação de todos os envolvidos na produção de saúde.

Além da escuta dos interessados em geral, gestores, trabalhadores e dos usuários no processo de medição dos serviços, sua participação no desenvolvimento dos instrumentos de avaliação também fica clara em nosso estudo.

Algumas questóes não abordadas pelo Qualiaids e que emergiram nos depoimentos dos usuários deveriam promover a revisão e o detalhamento de alguns indicadores para uma eventual nova versão do questionário, bem como a reflexão de gestores e trabalhadores de serviços especializados, no sentido de desenvolver estratégias que, por exemplo, otimizem as idas ao serviço de saúde, evitando faltas repetidas ao trabalho e a consequente exposição diante de colegas e patrôes, e, partindo da busca consentida e qualificada de faltosos, facilite seu retorno ao serviço e a continuidade da assistência. $\mathrm{O}$ volume de atestados fornecidos, por exemplo, pode refletir maior ou menor adequação do serviço à realidade de seus usuários em termos de horário de funcionamento e facilidade de agendamento. $\mathrm{O}$ número de visitas dos usuários ao serviço num determinado intervalo de tempo pode refletir alguma particularidade em sua condição clínica, mas pode evidenciar dificuldade de resolutividade e integralidade na atenção oferecida. 
Furtado e colaboradores (2013), a partir de estudo da elaboração colaborativa de indicadores para a avaliação da atenção em saúde mental, mesmo considerando o grande desafio da sua prática efetiva, mostraram a importância da utilização da estratégia em vários níveis do processo de aferição, que vai desde a proposta de variáveis-indicadores, passando pelo pré-teste dos instrumentos e pela análise dos dados, salientando também que a participação promove, ao final, o estímulo à apropriação dos resultados pelos envolvidos.

Alguns outros instrumentos usados em estudos de avaliação aprofundam questões importantes que não emergiram diretamente em nossas entrevistas, embora consideradas indiretamente, como é o caso do olhar para o trabalho de equipes multidisciplinares. Borges e colaboradores (2012) identificaram, entre usuários de três Serviços Especializados de Recife, uma grande preocupação com a fragmentação da atenção e, principalmente, do sujeito da atenção. A abordagem do sujeito na sua integralidade foi considerada deficiente, tanto por técnicos quanto por usuários dos serviços estudados. Na nossa população, o trabalho realizado por enfermeiros, nutricionistas, profissionais médicos não infectologistas e outros foi levantado como indicador de qualidade.

O estudo de Figueiredo e colaboradores (2014), por sua vez, encontrou debilidades mais relacionadas com a gestão do cuidado em um enfoque mais centrado nos profissionais médicos, nos exames e no acesso aos antirretrovirais, também pontuando a necessidade de um cuidado mais integral e integrador, enquanto usuários do SAT aqui entrevistados identificaram barreiras distintas e mais relacionadas com a operacionalização do cuidado.

Reconhecer a importância da participação permanente do usuário nas práticas avaliativas de serviços de saúde, com suas necessidades e demandas, suas interações com os profissionais de saúde e gestores, propicia a qualificação da assistência para os seus problemas de saúde, afirma seu direito de cidadania e destaca a integralidade e a humanização na produção de saúde. Valores como a qualidade do atendimento são apreendidos de modo necessariamente distinto em um instrumento de resposta do profissional ou do gestor e quando debatidos numa discussão focal em grupos com usuários dos serviços. Isso explica, em certa medida, que os emergentes grupais, ao serem comparados aos itens do Quailaids, tenham sido entendidos como recomendando a inclusão de questionamentos sobre qualidade do que é avaliado ali (como ao examinar os atendimentos de diferentes profissionais, por exemplo). Talvez não seja suficiente, porém, incluir 
uma avaliação de qualidade naqueles itens, se a informação não for buscada junto aos usuários dos serviços. A Política Nacional de Humanização (PNH) do SUS promove reflexões nesse sentido. É uma política transversal que indica a inseparabilidade entre gestão e atenção dos processos de produção de saúde, autonomia e protagonismo dos sujeitos (HECKERT; PASSOS; BARROS, 2009). Benevides e Passos (2005) indicam que o processo de produção de saúde deve levar em conta a pluralidade dos determinantes da saúde e a complexidade das relações entre todos os sujeitos envolvidos, e que tem como resultado, além da saúde, a produção de subjetividades. Este produto seria o ponto capital da proposta de humanização e que garante sua identidade (DESLANDES, 2005).

Os emergentes grupais dos encontros realizados permitem indicar a inclusão ou a qualificação de itens pesquisados no Qualiaids, como indicado nos Quadros 1, 2 e 3 neste artigo, considerando-se o formato e o modelo atual de coleta de dados para avaliação. Indo além, as manifestações dos usuários e o fato de ter sido possível indicar itens que complementam e qualificam o instrumento de avaliação atual também permitem propor que a estratégia seja modificada, com a inclusão de usuários dos serviços nos procedimentos de aferição. ${ }^{1}$

\section{Referências}

BARDIN, L. Análise de conteúdo. 5. ed. Lisboa: Edições 70, 2010.

BENEVIDES. R.; PASSOS, E. A humanização como dimensão pública das políticas de saúde. Ciênc. Saúde Coletiva, v. 10, n. 3, p. 561-71, 2005.

BORGES, M.J.L.; SAMPAIO, A.S.; GURGEL, I.G.D. Trabalho em equipe e interdisciplinaridade: desafios para a efetivação da integralidade na assistência ambulatorial às pessoas vivendo com HIV/Aids em Pernambuco. Ciênc. Saúde Coletiva, v. 17, n. 1, p. $147-56,2012$

- Ministério da Saúde. Diretrizes para o Fortalecimento das Ações de Adesão ao Tratamento para pessoas que vivem com HIV e AIDS. Brasília: Secretaria de Vigilância em Saúde. Programa Nacional de DST e Aids, 2007. Disponível em: <http://bvsms.saude.gov. br/bvs/publicacoes/diretrizes_tratamento_aids.pdf>. Acessado em: 28 jul. 2011.

Ministério da Saúde. Programa Nacional de DST e AIDS. Boletim epidemiológico AIDS/DST 2011 [internet]. Brasília: Ministério da Saúde, 2011. Disponível em: <www. aids.gov.br>. Acessado em: 28 dez. 2012.

. Ministério da Saúde. Programa Nacional de DST e AIDS. Boletim epidemiológico AIDS/DST 2014 [internet]. Brasília: Ministério da Saúde, 2014. Disponível em: <www. aids.gov.br>. Acessado em: 23 jun. 2017. 
Qualiaids: avaliação e monitoramento da qualidade da assistência ambulatorial em

AIDS no SUS/ Ministério da Saúde, Secretaria de Vigilância em Saúde, Programa Nacional de DST e AIDS [internet]. Brasília: Ministério da Saúde, 2008. Disponível em: <www.aids. gov.br>. Acessado em: 20 dez. 2012.

BOSI, M.L.M.; UCHIMURA, K.Y. Avaliação qualitativa de programas de saúde: contribuições para propostas metodológicas centradas na integralidade e na humanização. In: BOSI, M.L.M.; Mercado, F.J. (Orgs.). Avaliação qualitativa de programas de saúde: enfoques emergentes. Petrópolis: Vozes, 2006.

DESLANDES, S.F. O projeto ético-político da humanização: conceitos, métodos e identidade. Interface - Comun. Saúde Educ., v. 9, n. 17, p. 389-406, mar./ago. 2005.

ESHER, A.; SANTOS, E.M.; AZEREDO, T.B.; LUIZA, V.L.; OSORIO-DE-CASTRO, C.G.S.; OLIVEIRA, M.A. Logic models from an evaluability assessment of pharmaceutical services for people living with HIV/AIDS. Ciênc. Saúde Coletiva, v. 16, n. 12, p. 4833 4844, 2011.

ESHER, A.; SANTOS, E.M.; MAGARINOS-TORRES, R.; AZEREDO, T.B. Construindo Critérios de Julgamento em Avaliação: especialistas e satisfação dos usuários com a dispensação do tratamento do HIV/Aids. Ciênc. Saúde Coletiva, v. 17, n. 1, p. 203-214, 2012.

FIGUEIREDO, L.A. et al. Oferta de ações e serviços de saúde para o manejo do HIV/ Aids, sob a perspectiva dos usuários. Revista da Escola de Enfermagem da USP, v. 48, n. 6, p. $1026-1034,2014$

FURTADO, J.; ONOCKO-CAMPOS, R.T.; MOREIRA, M.I.B.; TRAPÉ, T.L. A elaboração participativa de indicadores para a avaliação em saúde mental. Cad. Saúde Pública, v. 29, n. 1, p. 102-110, 2013.

GARRIDO, P.B. et al. HIV/Aids, estigma e desemprego. Rev. Saúde Pública, v. 41, n. supl. 2, p. 72-9, 2007.

GRECO, D.B.; SIMĀO, M. A política brasileira de acesso universal ao tratamento da AIDS: desafios da sustentabilidade e perspectivas. AIDS, v. 21, n. supl. 4, p. S37-S45, 2007.

HECKERT, A.L.C.; PASSOS, E.; BARROS, M.E.B. Um seminário dispositivo: a humanização do Sistema Único de Saúde (SUS) em debate. Interface - Comun. Saúde Educ., v. 13, n. supl. 1, p. 493-502, 2009.

HENNINGTON, E.A. Acolhimento como prática interdisciplinar num programa de extensão universitária. Cad. Saúde Pública, v. 21, n. 1, p. 256-265, 2005.

MELCHIOR, R. et al. Avaliação da estrutura organizacional da assistência ambulatorial em HIV/Aids no Brasil. Rev. Saúde Pública. São Paulo, v. 40, n. 1, p. 143-151, fev. 2006. MISHIMA, S.M. A gerência de serviços de atenção primária à saúde como instrumento para a reorganização da assistência à saúde - o caso do Programa de Saúde da Família. 2003. $153 \mathrm{f}$. Tese (Doutorado) - Universidade de São Paulo, Ribeirão Preto, 2003. 

BASSO, C.R. Avaliação da qualidade da assistência no programa de AIDS: questôes para a investigação em serviços de saúde no Brasil. Cad. Saúde Pública, v. 20, n. supl. 2, p. S310-S321, 2004.

NEMES, M.I.B. et al. Avaliação de serviços de assistência ambulatorial em aids, Brasil: estudo comparativo 2001/2007. Rev. Saúde Pública. São Paulo, v. 47, n. 1, p. 137-146, fev. 2013.

PEDUZZI, M. et al. Trabalho em equipe na perspectiva da gerência de serviços de saúde: instrumentos para a construção da prática interprofissional. Physis. Rio de Janeiro, v. 21, n. $2,2011$.

PINHEIRO, R.; MARTINS, P.H.N. A centralidade do usuário na avaliação em saúde: outras abordagens. In: PINHEIRO, R.; MARTINS, P.H.N. (Orgs.). Avaliação em Saúde na Perspectiva do Usuário: abordagem multicêntrica. Rio de Janeiro: CEPESC/IMS-UERJ; Recife: Ed. Universitária UFPE; São Paulo: ABRASCO, 2009.

PINHEIRO, R.; LUZ, M.T. Práticas eficazes x modelos ideais: ação e pensamento na construção da integralidade. In: PINHEIRO, R.; MATTOS, R.A. (Orgs.). Construção da integralidade: cotidiano, saberes e práticas em saúde. Rio de Janeiro: UERJ/IMS; São Paulo: ABRASCO, 2007.

PINHEIRO, R.; GUIZARDI, F.L. Cuidado e integralidade: por uma genealogia de saberes e práticas no cotidiano. In: PINHEIRO, R.; MATTOS, R.A. (Orgs.). Cuidado: as fronteiras da integralidade. Rio de Janeiro: CEPESC/UERJ; São Paulo: ABRASCO, 2005. RAMOS, D.D.; LIMA, M.A.D. da S. Acesso e acolhimento aos usuários em uma unidade de saúde de Porto Alegre, Rio Grande do Sul, Brasil. Cad. Saúde Pública, v. 19, n. 1, fev. 2003.

SOUZA, E.C.F. de et al. Acesso e acolhimento na atenção básica: uma análise da percepção dos usuários e profissionais de saúde. Cad. Saúde Pública, v. 24, n. supl. 1, p. S100-S110, 2008. TEIXEIRA, R.R. Humanização e atenção primária à saúde. Ciênc. Saúde Coletiva, v. 10, n. 3, p. 585-97, 2005.

O acolhimento num serviço de saúde entendido como uma rede de conversações. In: PINHEIRO, R.; MATTOS, R.A. (Orgs.). Construção da integralidade: cotidiano, saberes e práticas em saúde. Rio de Janeiro: UERJ/IMS; São Paulo: ABRASCO, 2007.

VICTORA, C.G.; KNAUTH, D.R.; HASSEN, M.N.A. Pesquisa Qualitativa em Saúde: uma introdução ao tema. Porto Alegre: Tomo Editorial, 2000.

\section{Nota}

${ }^{1}$ L.O. Dossena coordenou o estudo, o desenvolvimento do projeto, as atividades de campo, a análise dos dados, a revisão de literatura e a redação da versão final do manuscrito. R.L Horta e N.T. Barcellos auxiliaram no desenvolvimento do projeto, acompanharam as atividades de campo e análise dos dados e participaram da redação da versão final do artigo. 


\section{Abstract}

Approaches between perception of users and items of the instrument for evaluation of Brazilian acquired immunodeficiency syndrome care services

This paper presents contents from the evaluation made by users from an Acquired Immunodeficiency Syndrome specialized care center in Southern Brazil, comparing perceptions of the groups with the dimensions of the electronic questionnaire employed in Brazil to evaluate this kind of service. The central perspectives were the comprehensiveness and humanization in health care services. Users were invited to focus groups and the transcriptions of the meetings were submitted to a thematic analysis. The quality of access and reception appeared prominently not captured by the employed instrument and influencing connection, treatment adherence and preference for the service. The demand pressure which impacts negatively on the relation among users and health team was also captured in detail as well as items of dissatisfaction, even the service being predominantly assessed as positive. The prejudice concerning people living with acquired immunodeficiency syndrome also stands out, highlighting the need for organization of specific health practices as well as further studies on the topic. This paper shows the relevance of including users in the evaluation of health care procedures for upgrading care and it also highlights items that could be used in the expansion and qualification of the instrument used in Brazil.

> Keywords: health facilities; human resources; quality assurance; health care; acquired immunodeficiency syndrome; focus groups. 


\section{ERRATA}

No artigo < Aproximações entre percepção de usuários e itens do instrumento para avaliação dos serviços brasileiros em síndrome de imunodeficiência adquirida>, com número de DOI: <http://dx.doi.org/10.1590/s0103-73312017000300015>, publicado no periódico $<$ Physis: Revista de Saúde Coletiva $>,<$ vol. 27>(<no. 3>): <661-683>>, na página <661 >:

Onde se lia

$<$ Nemora Teegnago Barcellos ${ }^{3}>$

\section{Leia-se:}

$<$ Nemora Tregnago Barcellos ${ }^{3}>$ 